Hydrol. Earth Syst. Sci., 17, 1229-1240, 2013

www.hydrol-earth-syst-sci.net/17/1229/2013/

doi:10.5194/hess-17-1229-2013

(c) Author(s) 2013. CC Attribution 3.0 License.

\title{
Snow accumulation/melting model (SAMM) for integrated use in regional scale landslide early warning systems
}

\author{
G. Martelloni ${ }^{1}{ }^{*}$, S. Segoni ${ }^{1}$, D. Lagomarsino ${ }^{1}$, R. Fanti ${ }^{1}$, and F. Catani ${ }^{1}$ \\ ${ }^{1}$ University of Firenze, Earth Sciences Department, Via La Pira 4, 50121 Firenze, Italy \\ *now at: University of Firenze, Department of Industrial Engineering (CSDC - Center of the Study of Complex Dynamics), \\ Via Santa Marta 3, 50139 Firenze, Italy
}

Correspondence to: S. Segoni (samuele.segoni@unifi.it)

Received: 26 July 2012 - Published in Hydrol. Earth Syst. Sci. Discuss.: 10 August 2012

Revised: 28 February 2013 - Accepted: 6 March 2013 - Published: 20 March 2013

\begin{abstract}
We propose a simple snow accumulation/melting model (SAMM) to be applied at regional scale in conjunction with landslide warning systems based on empirical rainfall thresholds.

SAMM is based on two modules modelling the snow accumulation and the snowmelt processes. Each module is composed by two equations: a conservation of mass equation is solved to model snowpack thickness and an empirical equation for the snow density. The model depends on 13 empirical parameters, whose optimal values were defined with an optimisation algorithm (simplex flexible) using calibration measures of snowpack thickness.

From an operational point of view, SAMM uses as input data only temperature and rainfall measurements, bringing about the additional benefit of a relatively easy implementation.

After performing a cross validation and a comparison with two simpler temperature index models, we simulated an operational employment in a regional scale landslide early warning system (EWS) and we found that the EWS forecasting effectiveness was substantially improved when used in conjunction with SAMM.
\end{abstract}

\section{Introduction}

In Italy landsliding is one of the most widespread natural hazards, responsible for casualties and major economic losses (Guzzetti, 2000); consequently, there is a clear need to set up effective landslide warning systems. Physically based conceptual models rely on a number of input parameters characterised by a spatial organisation that is difficult to correctly assess in large-scale distributed applications (Segoni et al., 2012). Therefore, they are mainly used in operational monitoring and warning systems that work at a slope (Damiano et al., 2012) or catchment scale (Segoni et al., 2009; Baum et al., 2010; Rossi et al., 2013). Conversely, regional scale landslide early warning systems are usually based on simpler but effective statistical or empirical correlations with rainfall (Keefer et al., 1987; Aleotti, 2004; Cannon et al., 2011; Martelloni et al., 2012; Lagomarsino et al., 2013), which is commonly accepted as the major cause of landslide triggering (Wieczorek, 1996). Such methodology is widely used at regional scale because it allows considering a single parameter (rainfall) to monitor and forecast landslide occurrence (Rosi et al., 2012).

However, in mid-latitude areas a not negligible number of landslides is commonly triggered by the water released after rapid snowmelt (Chleborad, 1997; Cardinali et al., 2000; Guzzetti et al., 2003; Kawagoe et al., 2009). This leads to the necessity of incorporating snow accumulation and melting modules into landslide regional scale early warning systems. Unfortunately, the coupling of snowmelt and landslide hazard models is not well established and only a few examples exist (Gokceoglu et al., 2005; Naudet et al., 2008; Kawagoe et al., 2009). However, in other fields of research, snow accumulation/depletion models have been implemented with various practical aims ranging from the estimation of hydrologic runoff (Marks et al., 1999; Zanotti et al., 2004; Garen and Marks, 2005; Li and Wang, 2011) to the study and forecasting of snow avalanches (Brun et al., 1989; Bartelt and Lehning, 2002; Rousselot et al., 2010; Takeuchi et al., 2011), 
the related soil erosion (Ceaglio et al., 2012), and to global atmospheric circulation and weather forecasts (Martin et al., 1996; Bernier et al., 2011).

Depending on the scopes, the scales and the available data, several snow accumulation/melting models have been proposed, and they can be grouped into two main categories. The most sophisticated are spatially distributed models based on equations of mass and energy balance (Bloschl et al., 1991; Zanotti et al., 2004; Garen and Marks, 2005; Herrero et al., 2009). These models, following a mechanistic approach, account for as many as possible physical and chemical processes involved in the building and depletion of the snowpack. Such models are rather complex and require several physical parameters including (but not limited to) topography, precipitation, air temperature, wind speed and direction, humidity, downwelling shortwave and longwave radiation, cloud cover, surface pressure. The determination of accurate values of these parameters, and their variation in space and time, is only possible for very well-equipped experimental test sites (Lakhankar et al., 2013); therefore, simplified approaches as temperature-index methods are also widely used (Kustas et al., 1994; Rango and Martinec, 1995; Hock, 1999, 2003; Jost et al., 2012). Those models use air temperature as an index to perform an empirical correlation with snowmelt and require only a few parameters (e.g. precipitation, air temperature, snow covered area). Temperature index methods are more simplistic than the aforementioned physical models; nevertheless, they can be used with good results and it has been shown that only a little additional improvement in model performance is achieved when adopting an energy balance approach (Hock, 2003).

In this paper we develop a simple snow accumulation/melting model (SAMM henceforth), to be integrated into a regional scale early warning system based on statistical rainfall thresholds for the occurrence of landslides.

The main objective of SAMM is not to obtain a distributed modelling of the snowpack, but the development of a methodology to modify the rain gauge rainfall measurements used as input data in landslide warning systems so as to take into account snow accumulation and depletion.

The paper first presents an overview of the study area, the landslide warning system, the quantity and quality of available experimental data. Then the snow accumulation/melting model is presented with emphasis on the adopted calibration procedure and on the identification of the optimal configuration. A comparison with a simple temperature index model and an improved temperature index model is also performed. The results of the calibration are presented and validated. Finally, the coupling of SAMM to the SIGMA landslide warning system (Martelloni et al., 2012) is shown and discussed.

\section{Materials and methods}

\subsection{Case study}

Emilia Romagna $\left(22446 \mathrm{~km}^{2}\right)$ is an Italian region (Fig. 1) highly prone to landslides. Its hills and mountains (Northern Apennines) are affected by both shallow and deep seated landslides: the former are usually triggered by short and exceptionally intense rainstorms and the latter by moderate but exceptionally prolonged rainfalls (Martelloni et al., 2012).

To manage the hazard related to both kinds of landslides, the Emilia Romagna Civil Protection Agency uses, among the others, a warning system called SIGMA (Sistema Integrato Gestione Monitoraggio Allerta, "Integrated service for managing and monitoring alerts") (Martelloni et al., 2012). The system is based on a series of statistical rainfall thresholds, which are compared with two different periods of cumulative rainfall: (i) daily checks of the 1 day, 2 days and 3 days cumulative rainfall, related to the occurrence of shallow landslides; (ii) a series of daily checks over a longer and variable time window (up to 243 days, depending on the seasonality), related to the activation or reactivation of deep seated landslides in low-permeability terrains. A decisional algorithm combines different thresholds (corresponding to rainstorms with increasing severity) and issues a warning level in accordance with the regional civil protection guidelines. SIGMA combines in its decisional algorithm rainfall forecasts and hourly rainfall measurements received from an automated regional network. The hilly and mountainous territory of Emilia Romagna is partitioned into 19 territorial units (TUs), which have a typical areal extension of a few hundred squared kilometres and can be considered quite homogeneous from a geomorphological and meteorological point of view (Fig. 1).

All TUs have a pluviometric regime characterised by rainy autumns and springs and dry summers, but the average precipitations are very different (Fig. 2). In most TUs, snow is an exceptional phenomenon and when it occurs the snowpack is likely to melt within a few days. On the contrary, in a few TUs characterised by a higher mountain territory, winter snow is recurrent and may lead to a consistent and long-lasting snowpack that melts away in spring.

Each TU has a reference rain gauge and a set of individually calibrated rainfall thresholds, therefore the warning system is able to issue independent alert levels for each TU. The choice of using a unique rain gauge for each TU certainly represents a limit of the system, but it helps to standardize the accuracy of the model, to simplify its management and to better understand its outputs (Martelloni et al., 2012). Further details on the SIGMA warning system and on the study area can be found in Martelloni et al. (2012).

During the test phase of SIGMA, it was observed that a consistent part of the errors committed by the warning system could be related to snow accumulation and depletion. All TUs potentially affected by snowmelt triggered landslides 


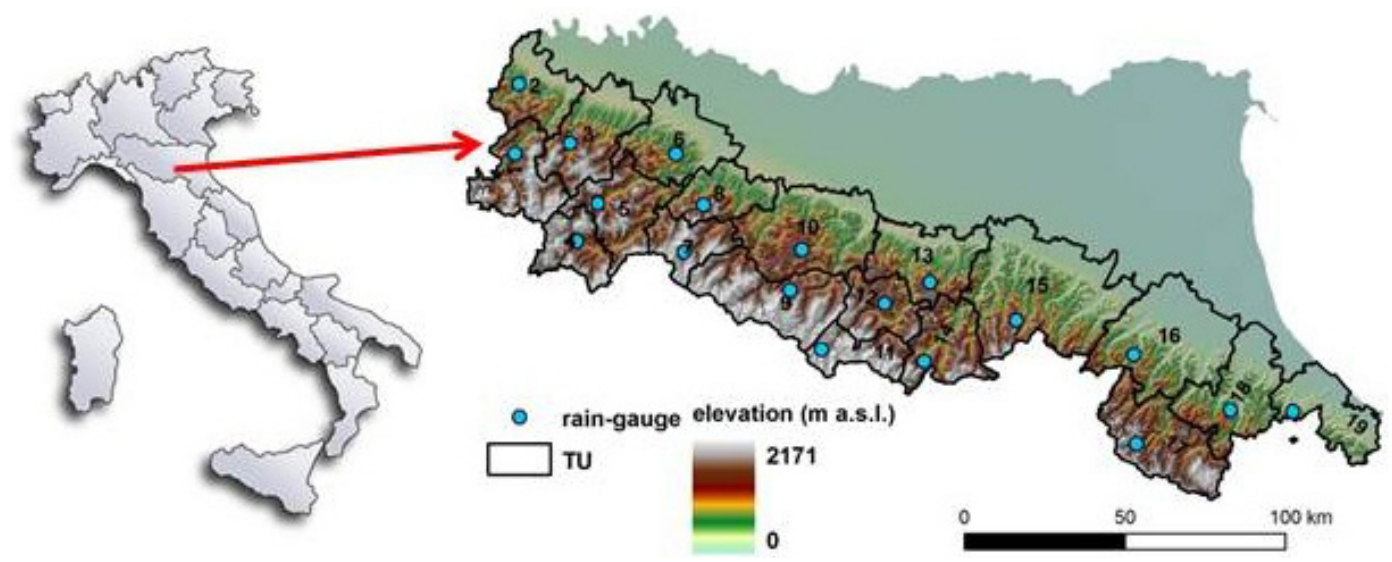

Fig. 1. The Emilia Romagna region. The study area is partitioned into 19 territorial units (TU), each provided with a reference rain gauge.

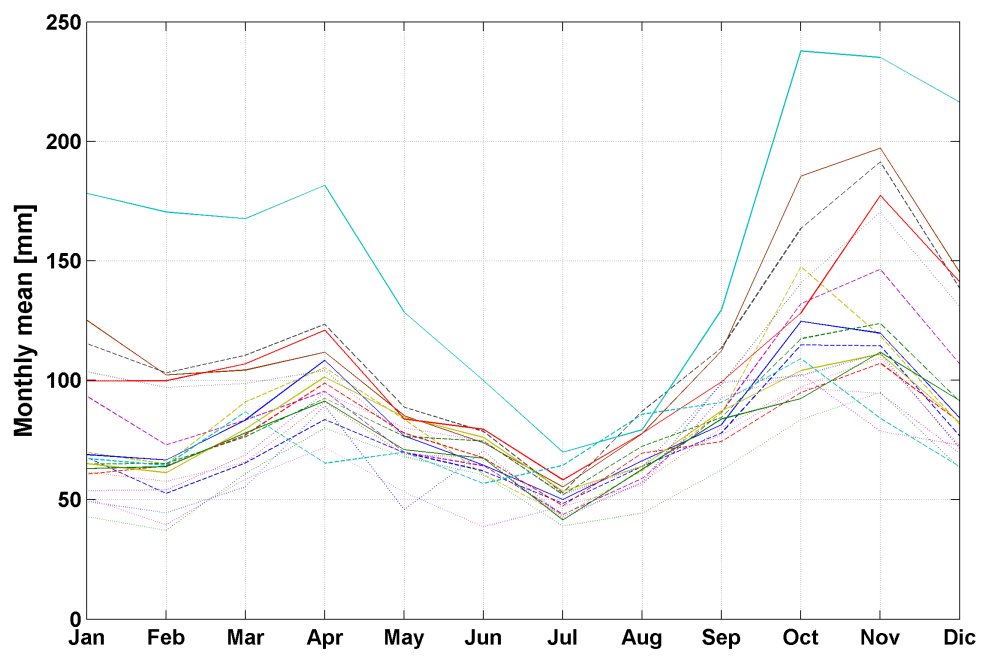

\begin{tabular}{|ccc|}
\hline T.U. & M.A.P. $(\mathrm{mm})$ & Elevation $(\mathrm{m})$ \\
\hdashline$-1^{*}$ & 901 & 270 \\
2 & 861 & 410 \\
3 & 895 & 600 \\
$4^{\star}$ & 1385 & 521 \\
$5^{\star}$ & 1063 & 597 \\
6 & 990 & 434 \\
$7^{\star}$ & 1366 & 618 \\
$8^{\star}$ & 1005 & 381 \\
$9^{\star}$ & 997 & 704 \\
10 & 940 & 580 \\
$11^{*}$ & 2064 & 1083 \\
$12^{\star}$ & 904 & 678 \\
13 & 972 & 700 \\
14 & 1217 & 352 \\
$15^{\star}$ & 860 & 741 \\
$16^{*}$ & 923 & 556 \\
$17^{\star}$ & 1295 & 735 \\
$18^{\star}$ & 923 & 364 \\
19 & 808 & 117 \\
* heated rain gauge \\
\multicolumn{3}{c}{} \\
\hline
\end{tabular}

Fig. 2. Pluviometric regime of the 19 territorial units of the Emilia Romagna region.

are equipped with heated rain gauges and in case of solid precipitations (i.e. snow), they automatically provide the system with a measure of the snow water equivalent, which is not distinguished from rainfall. It was observed that this occurrence leads to several false alarms: the thresholds can be overcome without any landslide occurrence, since water actually accumulates in the snowpack and it is not transferred to the soil. On the other side, several missed alarms were observed during snow melting: the released water triggered some landslides during the days with scarce or absent rainfalls (thus thresholds were not exceeded).

To overcome these problems, a simple snow accumulation/melting model (SAMM) was developed and integrated within the SIGMA early warning system.

Given

i. the scale of the analysis (regional scale);

ii. the aforementioned characteristics of the adopted warning system (statistical rainfall thresholds developed for a network of rain gauges each pertaining to a territory with a typical areal extension of few hundreds $\mathrm{km}^{2}$ );

iii. the limitation of experimental data (only snow thickness, air temperature and rainfall amount are measured and recorded at few discrete points, only in a few cases corresponding with the rain gauge stations),

SAMM is intended to be an operative computational module to adjust the rainfall measurements provided by the heated rain gauges when snow-related phenomena are present.

\subsection{Snow accumulation/melting model (SAMM)}

In this model three different terms of mass are identified: the mass accumulated in the snowpack $m_{\mathrm{s}}$, the input flow mass $m_{\mathrm{s}}^{\text {in }}$, and the output flow mass $m_{\mathrm{s}}^{\text {out }}$. They can be expressed by the following equations: 


$$
\left\{\begin{array}{l}
m_{\mathrm{s}}=\rho_{\mathrm{s}} \cdot A \cdot H_{\mathrm{s}} \\
m_{\mathrm{s}}^{\text {in }}=\rho_{\mathrm{s} 0} \cdot A \cdot H^{\text {in }} \\
m_{\mathrm{s}}^{\text {out }}=\rho_{\mathrm{s}} \cdot A \cdot H^{\text {out }}
\end{array}\right.
$$

where $\rho_{\mathrm{s}}, \rho_{\mathrm{s} 0}$ are, respectively, the densities of the snowpack and of the newly fallen snow; $A$ is the area of the considered section; and $H_{\mathrm{s}}$ the snow height or snowpack thickness. For the principle of mass conservation, the mass variation in the snowpack $\mathrm{d} m_{\mathrm{S}} / \mathrm{d} t$ is equal to the difference between the input mass flow $Q^{\text {in }}$ and the output mass flow $Q^{\text {out }}$.

$\frac{\mathrm{d} m_{\mathrm{s}}}{\mathrm{d} t}=Q^{\mathrm{in}}-Q^{\mathrm{out}}$

Equation (2) can be expressed in terms of the discrete time variable $t$ :

$\rho_{\mathrm{S}}\left(t_{1}\right) \cdot H_{\mathrm{S}}\left(t_{1}\right)-\rho_{\mathrm{S}}(t) \cdot H_{\mathrm{S}}(t)=\rho_{\mathrm{s} 0} \cdot H^{\text {in }}(t)-\rho_{\mathrm{S}} \cdot H^{\text {out }}(t)$,

where $t_{1}=t+1$.

$H_{\mathrm{S}}\left(t_{1}\right)$ is then given by

$H_{\mathrm{S}}\left(t_{1}\right)=\frac{\rho_{\mathrm{S}}(t)}{\rho_{\mathrm{S}}\left(t_{1}\right)} \cdot H_{\mathrm{S}}(t)+\frac{\rho_{\mathrm{W}}}{\rho_{\mathrm{S}}\left(t_{1}\right)} \cdot H_{\mathrm{W}}(t)-\frac{\rho_{\mathrm{S}}(t)}{\rho_{\mathrm{S}}\left(t_{1}\right)} \cdot H^{\text {out }}(t)$,

where $H^{\text {in }}$ has been expressed as a function of the amount of rain $H_{\mathrm{w}}$, considering the respective water and snow densities $\rho_{\mathrm{W}}$ and $\rho_{\mathrm{s} 0}$ :

$\frac{\rho_{\mathrm{w}}}{\rho_{\mathrm{s} 0}}=\frac{\frac{m}{H_{\mathrm{w}} \cdot A}}{\frac{m}{H^{\mathrm{in}} \cdot A}}=\frac{H^{\mathrm{in}}}{H_{\mathrm{w}}} \Rightarrow H^{\mathrm{in}}=\frac{\rho_{\mathrm{w}}}{\rho_{\mathrm{s} 0}} \cdot H_{\mathrm{w}}$.

In Eq. (4) the average density of the snowpack $\rho_{\mathrm{s}}$ and output term $H^{\text {out }}$ are not known. The variation in time of the average snowpack density has been considered using empirical equations (see the accumulation module below). $H^{\text {out }}(t)$ has been taken into account using empirical equations for depletion process (see melting module below).

\subsubsection{Accumulation module}

Various techniques and different approaches have been employed in the attempt to explain meteorological controls over new snow density. Bartlett et al. (2006) use an exponential relationship between newly fallen snow density $\left(\rho_{\mathrm{s} 0}\right)$ and air temperature $\left(T_{\mathrm{a}}\right)$ developed by Hedstrom and Pomeroy (1998) from the data of Schmidt and Gluns (1991) and the US Army Corps of Engineers (1956). This approach was combined with the definition of a threshold temperature below which precipitation turns from pure rain to snow, as proposed by Gustafsson et al. (2004). The density of the new fallen snow is then defined as

$\rho_{\mathrm{s} 0}\left(t_{1}\right)=k_{\rho 0} \cdot \exp \left(k_{\exp } \cdot\left(T_{\mathrm{a}}\left(t_{1}\right)-T_{0}\right)\right)$,

where $T_{0}$ is a threshold temperature under which the precipitation can be considered solid, and the values of the empirical parameters $k_{\rho 0}$ and $k_{\text {exp }}$ are obtained by the model calibration (Sect. 2.3).

Equation (6) provides a good approximation for temperature values higher than $-5^{\circ} \mathrm{C}$ : this result is due to the typical temperature values experimentally observed in the study area and represented in the dataset used for the model calibration.

The processes linked to the accumulation/depletion of the snowpack (e.g. compression of the snowpack due to newly fallen snow and effects of rainfall) were modelled by identifying limiting and inhibitory factors according to a kinetic approach.

A limiter $X$ and an inhibitor $Y$ are, respectively, defined in a kinetics process as the ratios $r_{l}$ and $r_{i}$ :

$r_{l}=\frac{X}{k+X} \quad r_{i}=\frac{k}{k+Y}$.

$X$ and $Y$ play complementary roles: the process goes at full speed $\left(r_{l}\right.$ and $r_{i} \rightarrow 1$ ) for large $X$ values and for small $Y$ values, and slows down towards stability $\left(r_{l}\right.$ and $\left.r_{i} \rightarrow 0\right)$ for small $X$ values and large $Y$ values.

Concerning the compression process, the snowpack depth $H_{\mathrm{s}}$ is a limiter (compression is favoured by large $H$ values due to a greater quantity of matter), while the snow density acts as an inhibitor (since a high density tends to oppose to the process of gravitational compression).

Therefore, the compression term due to snowpack weight is expressed by

$k_{\rho 1} \frac{H_{\mathrm{S}}(t)}{k_{\rho 2}+H_{\mathrm{S}}(t)} \cdot \frac{k_{\rho}}{k_{\rho}+\rho_{\mathrm{S}}(t)}$,

where $k_{\rho 1}, k_{\rho 2}, k_{\rho}$ are empirical parameters.

The average density of the snowpack $\rho_{\mathrm{s}}$ is a function of time, and is expressed as a weighted average of the density in the previous time interval and the density of new fallen snow:

$\rho_{\mathrm{S}}\left(t_{1}\right)=\frac{H_{\mathrm{S}}(t)\left(\rho_{\mathrm{S}}(t)+k_{\rho 1} \frac{H_{\mathrm{S}}(t)}{k_{\rho 2}+H_{\mathrm{S}}(t)} \frac{k_{\rho}}{k_{\rho}+\rho_{\mathrm{s}}(t)}\right)+H_{\mathrm{W}}\left(t_{1}\right) \rho_{\mathrm{W}}}{H_{\mathrm{S}}(t)+\frac{H_{\mathrm{W}}\left(t_{1}\right) \rho_{\mathrm{W}}}{\rho_{s 0}\left(t_{1}\right)}}$

where $k_{\rho 1}, k_{\rho 2}, k_{\rho}$ are empirical parameters.

Taking into consideration the conservation of mass, the snowpack depth as a function of time is then given by

$H_{\mathrm{S}}\left(t_{1}\right)=\frac{1}{\rho_{\mathrm{S}}\left(t_{1}\right)}\left(H_{\mathrm{S}}(t) \rho_{\mathrm{S}}(t)+H_{\mathrm{W}}\left(t_{1}\right) \cdot \rho_{\mathrm{W}}\right)$.

\subsubsection{Melting module}

Concerning the melting process, the snowpack density equation takes into account the compression term due to snowpack weight (Eq. 8) and the effects of percolating snowmelt, which was modelled according to a kinetic approach (Eq. 7): the temperature acts as a limiting factor, because as a result of the melting process, water percolates in the snowpack and 
causes an additional effect of compression. This process, increasing with temperature, is expressed by the term:

$$
\frac{T_{\mathrm{a}}\left(t_{1}\right)}{k_{t}+T_{\mathrm{a}}\left(t_{1}\right)},
$$

where $k_{t}$ is an empirical parameter.

Then, the equation of snowpack density can be expressed as

$$
\rho_{\mathrm{S}}\left(t_{1}\right)=\rho_{\mathrm{S}}(t)+k_{\rho 1} \frac{H_{\mathrm{S}}(t)}{k_{\rho 2}+H_{\mathrm{S}}(t)} \frac{k_{\rho}}{k_{\rho}+\rho_{\mathrm{S}}(t)} \frac{T_{\mathrm{a}}\left(t_{1}\right)}{k_{t}+T_{\mathrm{a}}\left(t_{1}\right)} .
$$

Unlike Eq. (9), Eq. (12) is not a weighted average, because there is a net variation of mass due to melting.

The melting process depends on several factors. In this model we take into consideration the temperature, the rain and the amount of mass.

The influence of temperature is introduced as a power term expressed by the difference between air temperature and the threshold $T_{0}$ :

$\Delta T^{*}=\left(T_{\mathrm{a}}(t)-T_{0}\right)^{k 1}$.

The rain, if present, contributes to the snow melting. As a result, the term $\alpha$ is introduced as a limiter (Eq. 7):

$\alpha=\frac{H_{\mathrm{w}}\left(t_{1}\right)}{k_{\mathrm{w}}+H_{\mathrm{w}}\left(t_{1}\right)}$.

Finally, to simulate the possible effects of refreezing that increases with density and height of the snowpack, the amount of mass (expressed as the product of height $H_{\mathrm{s}}$ and density $\rho_{\mathrm{S}}$ ) is considered an inhibitor (Eq. 7) of the dissolution process and can be expressed as the factor

$\beta=\frac{k_{\mathrm{s} 1}}{k_{\mathrm{s} 1}+H_{\mathrm{s}}(t) \rho_{\mathrm{s}}(t)}$.

Equation (13) and $\alpha$ and $\beta$ factors (Eqs. 14 and 15) are then combined in the final equation, which expresses the amount of thawed mass $H_{\mathrm{ww}}$ per unit area:

$H_{\mathrm{ww}}\left(t_{1}\right)=\left(k_{2} \Delta T^{*}+k_{3} \alpha\right) \beta$.

At each time step, the height of the snowpack $H_{\mathrm{s}}$ is updated by subtracting the amount of melted snowpack $\left(H_{\mathrm{ww}}\right)$ :

$H_{\mathrm{S}}\left(t_{1}\right)=\frac{1}{\rho_{\mathrm{S}}\left(t_{1}\right)}\left(H_{\mathrm{S}}(t) \rho_{\mathrm{s}}(t)-H_{\mathrm{ww}}\left(t_{1}\right)\right)$

In Eqs. (13), (14), (15) and (16), $k_{1}, k_{2}, k_{3}, k_{\mathrm{w}}, k_{\mathrm{s} 1}$ are empirical parameters.

SAMM was conceived to work at hourly time steps, corresponding to the maximum temporal resolution of data at our disposal. From an operational point of view, temperature and rainfall are the only parameters provided in real-time by the regional sensor networks, therefore they are the only timedependent variables used by the model. All the 13 empirical parameters identified in the model are constants, which are actually used to better calibrate the response of the model. An overview of the 13 parameters is provided in Table 1.

\subsection{Parametric identification of the model}

The depth of the snowpack measured by a network of instrumented sensors located in correspondence of the rain gauges (Fig. 1) was used to calibrate the model: $H_{\mathrm{s}}$ is determined by the temperature, the rainfall, the state variable $\rho_{\mathrm{s}}$, and the 13 constants of the model $P=p 1, p 2, \ldots, p 13 \in \Re 13$, whose values are determined by the calibration process.

The functional error $E(\boldsymbol{P})$ is expressed by

$E(\boldsymbol{P})=\frac{1}{N} \sum_{i=1}^{N} w_{i} \varepsilon_{i}^{2}=\frac{1}{N} \sum_{i=1}^{N} w_{i}\left(H_{i}^{\exp }-H_{i}^{\bmod }(\boldsymbol{x}, \boldsymbol{P})\right)^{2}$

where $H_{i}^{\exp }$ and $H_{i}^{\text {mod }}$ represent the experimental and the modelled snowpack height, respectively; $N$ is the number of data; $w_{i}$ is the weight of error $\varepsilon_{i}$. An optimisation algorithm (Flexible Optimized Simplex) (Nelder and Mead, 1965; Himmelblau, 1972; Marsili-Libelli, 1992) was used to estimate the values of the parameters which minimise the functional error $E(\boldsymbol{P})$ (Eq. 18). This heuristic search algorithm is based on the construction of a simplex, which can be defined as a n-dimensional polytope with the smallest possible number of vertices $(n+1)$ : given the domain of the functional error, in our case the simplex is 13-dimensional (14 vertices). Once an initial simplex is defined (by assigning an initial condition to each parameter), the algorithm updates the simplex step by step, replacing the worst point, i.e. the point with the highest functional error.

The simplex flexible algorithm is an effective approach with several points of strength: it is effective in finding the absolute minimum as it does not stop when relative minimum points are found; it can manage parameter values with different order of magnitude (problems with "high curvature" and "narrow valleys"); the computations are not time demanding as the algorithm requires a limited number of functional assessments.

The algorithm stops the research process when all vertices of the simplex have the same functional error (flatness test of simplex).

The presented methodology could be easily applied elsewhere, provided the availability of the data needed for real time implementation (temperature and rainfall) and for the calibration process (historical snow depth measurements).

\section{Results and discussion}

\subsection{Results of calibration and validation}

The calibration of the model was performed using the dataset of measures recorded by the Doccia di Fiumalbo rain gauge station during the year 2009. Those data were provided by ARPA ("Agenzia Regionale Prevenzione e Ambiente" - Regional Agency Prevention and Environment). 
Table 1. The optimal configuration of SAMM obtained with two different parametric identification techniques.

\begin{tabular}{|c|c|c|c|c|}
\hline Parameters & Explanation & Equation & $\begin{array}{r}\text { Optimum value } \\
\text { (Simplex) }\end{array}$ & $\begin{array}{r}\text { Optimum value } \\
\text { (SIMPSA) }\end{array}$ \\
\hline$k_{1}$ & Influence of $T_{\text {air }}$ on melting process & 13 & 3.25 & 3.40 \\
\hline$k_{2}[\mathrm{M}] /\left[\mathrm{L}^{2}\right][\Theta]$ & Influence of $T_{\text {air }}$ on melting process & 16 & 0.0009 & 0.0010 \\
\hline$k_{3}[\mathrm{M}] /\left[\mathrm{L}^{2}\right]$ & Influence of rain on melting process & 16 & 15.87 & 15.89 \\
\hline$k_{\rho 1}[\mathrm{M}] /\left[\mathrm{L}^{3}\right]$ & Compression due to snowpack depth & 8 & 0.43 & 0.44 \\
\hline$k_{\rho 2}[\mathrm{~L}]$ & Compression due to snowpack depth & 8 & 1.40 & 1.45 \\
\hline$k_{\rho}[\mathrm{M}] /\left[\mathrm{L}^{3}\right]$ & Compression due to snowpack depth & 8 & 0.30 & 0.32 \\
\hline$k_{t}[\Theta]$ & Compression due to rainfall & 11 & 0.11 & 0.11 \\
\hline$k_{\mathrm{W}}[\mathrm{L}]$ & Influence of rain on melting process & 14 & 0.040 & 0.038 \\
\hline$k_{\mathrm{S} 1}[\mathrm{M}] /\left[\mathrm{L}^{2}\right]$ & Influence of increased density on refreezing & 15 & 200.02 & 200.34 \\
\hline$k_{\rho 0}[\mathrm{M}] /\left[\mathrm{L}^{3}\right]$ & Influence of $T_{\text {air }}$ on density of the new fallen snow & 6 & 165.02 & 180.00 \\
\hline$k_{\exp }$ & Influence of $T_{\text {air }}$ on density of the new fallen snow & 6 & 0.049 & 0.049 \\
\hline$\rho_{\mathrm{S}}(t=0)\left(\mathrm{kg} \mathrm{m}^{-3}\right)$ & Initial density & 3 & 94.01 & 160.04 \\
\hline$T_{0}\left({ }^{\circ}\right)$ & Threshold temperature & 6 & 0.30 & 0.28 \\
\hline
\end{tabular}

\subsubsection{Choice of the calibration algorithm}

For comparison, in addition to the aforementioned Flexible Optimized Simplex (Sect. 2.3), another calibration process of SAMM was performed using a different methodology: the SIMPSA (Cardoso et al., 1996), an optimisation model based on the combination of a nonlinear simplex and simulated annealing algorithms. Both optimisation algorithms defined similar values of the empirical parameters (Table 1) and only little differences could be noticed in the modelled snowpack evolution (Figs. 3 and 4).

To identify the best calibration algorithm (and relative model configuration), a validation was carried out over an independent dataset recorded by the Febbio station. The quality of these data was poorer than that observed in the calibration dataset: an hourly mean and 10-day moving average with exponential weights was used to reduce noise and to overcome the problem of small periods of missing data (Fig. 5).

The validation statistics are shown in Table 2 and prove that the best configuration of SAMM was obtained using the simplex flexible calibration algorithm (Sect. 2.3). According to Ryan et al. (2008), an error of $8.8 \mathrm{~cm}$ (this value corresponds to the mean absolute error observed for SAMM validation) is within the measurement errors of the rain gauges.

\subsubsection{Cross validation}

Since in most TUs the reference rain gauges of the regional warning system do not have data for a specific calibration, we tried to identify a representative dataset that could be used for calibrating the model to be applied to the whole region.

We therefore performed a distinct calibration for each measurement station (namely, six), for which the data required for the model calibration (snowpack thickness, rainfall and air temperature) were available. For each station we obtained a specific set of values for the 13 parameters.
Table 2. Mean snow depth and mean absolute error for the validation dataset.

\begin{tabular}{lrrr}
\hline & $\begin{array}{r}\text { Experimental } \\
\text { data }\end{array}$ & $\begin{array}{r}\text { SIMPLEX } \\
\text { calibration }\end{array}$ & $\begin{array}{r}\text { SIMPSA } \\
\text { calibration }\end{array}$ \\
\hline $\begin{array}{l}\text { Mean snow } \\
\text { depth }(\mathrm{cm})\end{array}$ & 41.2 & 44.9 & 32.9 \\
\hline $\begin{array}{l}\text { Mean absolute } \\
\text { error }(\mathrm{cm})\end{array}$ & - & 8.8 & 10.4 \\
\hline
\end{tabular}

Table 3 lists, for each station, all the parameters values, their range, the percentage of variability, the aspect and the elevation. In general the parameters values show a very limited variability from a measurement station to another: for example the values of the threshold temperature $T_{0}$, which is one of the most important parameters, range from $0.299^{\circ} \mathrm{C}$ to $0.305^{\circ} \mathrm{C}$. In only a few cases, parameter values show significant variations $\left(\rho_{\mathrm{s}}, k_{1}, k_{\rho 0}\right)$, which could only in a particular circumstance be clearly put in relation with the different geographical features of the measurement station: $k_{1}$ is related to the influence of air temperature on the melting process, its values are higher for southerly stations. All other parameters are mainly related to gravitational phenomena, as a consequence they do not show an evident trend related to elevation or aspect. This could be considered evidence of the robustness of the model and the calibration algorithm adopted.

To further corroborate this outcome and to identify the most appropriate configuration for the parameterisation of the regional scale model, we performed a cross validation: each set of parameters obtained with the calibration of a specific station was applied to all the remaining stations and errors were calculated (Table 3). Results show that the best performances are obtained using the optimum configuration identified for the Doccia di Fiumalbo station (Table 3). The 
Table 3. Parameters values, aspect, elevation and total mean error for each station used in the cross validation.

\begin{tabular}{|c|c|c|c|c|c|c|c|c|}
\hline & Monteacuto & L. Pratignano & Lagdei & Piandelagotti & Loiano & $\begin{array}{r}\text { Doccia } \\
\text { Fiumalbo }\end{array}$ & Range & Variability $(\%)$ \\
\hline$k_{1}$ & 3.23 & 3.23 & 3.27 & 3.55 & 3.56 & 3.25 & 0.33 & 9.3 \\
\hline$k_{2}$ & $9.2 \times 10^{-4}$ & $9.1 \times 10^{-4}$ & $9.5 \times 10^{-4}$ & $9.6 \times 10^{-4}$ & $9.5 \times 10^{-4}$ & $9.3 \times 10^{-4}$ & $0.4 \times 10^{-4}$ & 4.8 \\
\hline$k_{3}$ & 15.77 & 16.35 & 16.30 & 16.27 & 15.96 & 15.87 & 0.58 & 3.5 \\
\hline$k_{\rho 1}$ & 0.43 & 0.44 & 0.44 & 0.45 & 0.44 & 0.43 & 0.02 & 3.6 \\
\hline$k_{\rho 2}$ & 1.39 & 1.42 & 1.42 & 1.42 & 1.41 & 1.40 & 0.03 & 2.1 \\
\hline$k_{\rho}$ & 0.30 & 0.31 & 0.31 & 0.31 & 0.30 & 0.30 & 0.01 & 3.3 \\
\hline$k_{t}$ & 0.11 & 0.11 & 0.11 & 0.11 & 0.11 & 0.11 & 0.00 & 0 \\
\hline$k_{\mathrm{W}}$ & 0.040 & 0.040 & 0.041 & 0.041 & 0.041 & 0.040 & 0.001 & 2.3 \\
\hline$k_{\mathrm{s} 1}$ & 198.92 & 199.91 & 212.30 & 206.92 & 203.21 & 200.02 & 13.39 & 6.3 \\
\hline$k_{\rho 0}$ & 164.25 & 175.62 & 169.25 & 167.95 & 162.67 & 165.02 & 12.95 & 7.4 \\
\hline$k_{\exp }$ & 0.049 & 0.050 & 0.050 & 0.050 & 0.050 & 0.049 & 0.001 & 2.4 \\
\hline$\rho_{\mathrm{S}}(t=0)\left(\mathrm{kg} \mathrm{m}^{-3}\right)$ & 117.68 & 100.11 & 98.01 & 101.01 & 100.90 & 94.01 & 23.67 & 20.1 \\
\hline$T_{0}\left(^{\circ}\right)$ & 0.299 & 0.298 & 0.305 & 0.304 & 0.301 & 0.300 & 0.0066 & 2.2 \\
\hline $\begin{array}{l}\text { Elevation } \\
\text { (m a.s.l.) }\end{array}$ & 900 & 1319 & 1252 & 1219 & 741 & 1371 & 630 & 45.95 \\
\hline Aspect & NW & $\mathrm{W}$ & $\mathrm{NE}$ & $\mathrm{S}$ & SE & $\mathrm{W}$ & & \\
\hline Error $(\mathrm{cm})$ & 11.3 & 10.6 & 10.4 & 14.5 & 14.5 & 10.1 & & \\
\hline
\end{tabular}
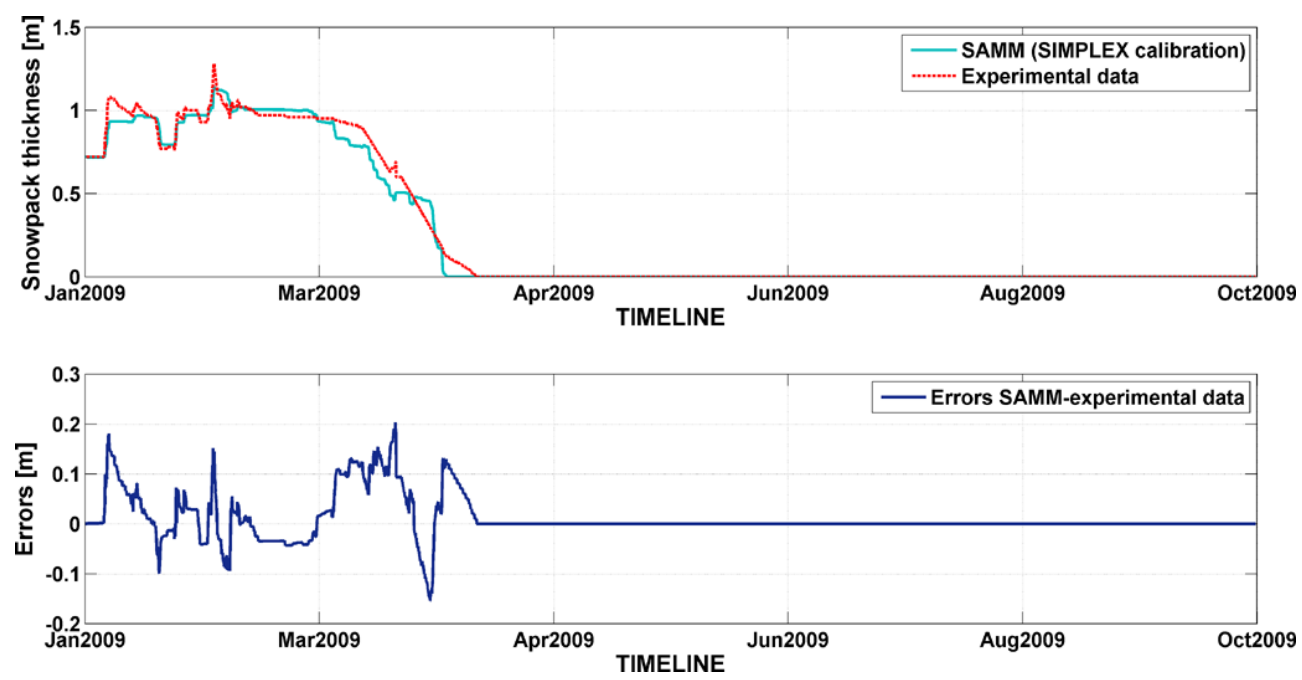

Fig. 3. Calibration of the model with the event January 2009-March 2009 registered by the Doccia di Fiumalbo station, using simplex flexible algorithm.

other configuration sets provided similar results, except for the two stations with a southerly aspect, in which mean absolute error increased by about $+50 \%$.

\subsubsection{Sensitivity analysis}

A further test on the robustness of the model was performed applying a static and dynamic sensitivity analysis.

In the static analysis, the sensitivity function $S(\boldsymbol{P})$ is evaluated:

$S(\boldsymbol{P})=\frac{1}{N} \sum_{t=1}^{N}\left|H_{\mathrm{t}}(\boldsymbol{x}, \boldsymbol{P})-H_{\mathrm{t}}\left(\boldsymbol{x}, \boldsymbol{P}^{\mathrm{nom}}\right)\right|$, where $H_{\mathrm{t}}\left(\boldsymbol{x}, \boldsymbol{P}^{\text {nom }}\right)$ is the nominal trajectory and $H_{\mathrm{t}}(\boldsymbol{x}, \boldsymbol{P})$ represents every trajectory obtained perturbing a parameter. The differences of each temporal step are added on a time interval of length $N$.

This analysis shows that errors are contained: for instance, Fig. 6 shows that for a wide range of $T_{0}$ (threshold temperature) and $k_{1}$ values close to their nominal values, the maximum mean error is below $10 \mathrm{~cm}$ (corresponding to $10 \mathrm{~mm}$ of equivalent rainfall).

The effects of the change of the threshold temperature $T_{0}$ are displayed in Fig. 7: the nominal value of $0.3^{\circ} \mathrm{C}$ is incremented up to $1.3^{\circ}$ and decreased to $-0.7^{\circ} \mathrm{C}$. The threshold temperature is the most important factor of SAMM; therefore, the model is sensible to this parameter, but it also shows 

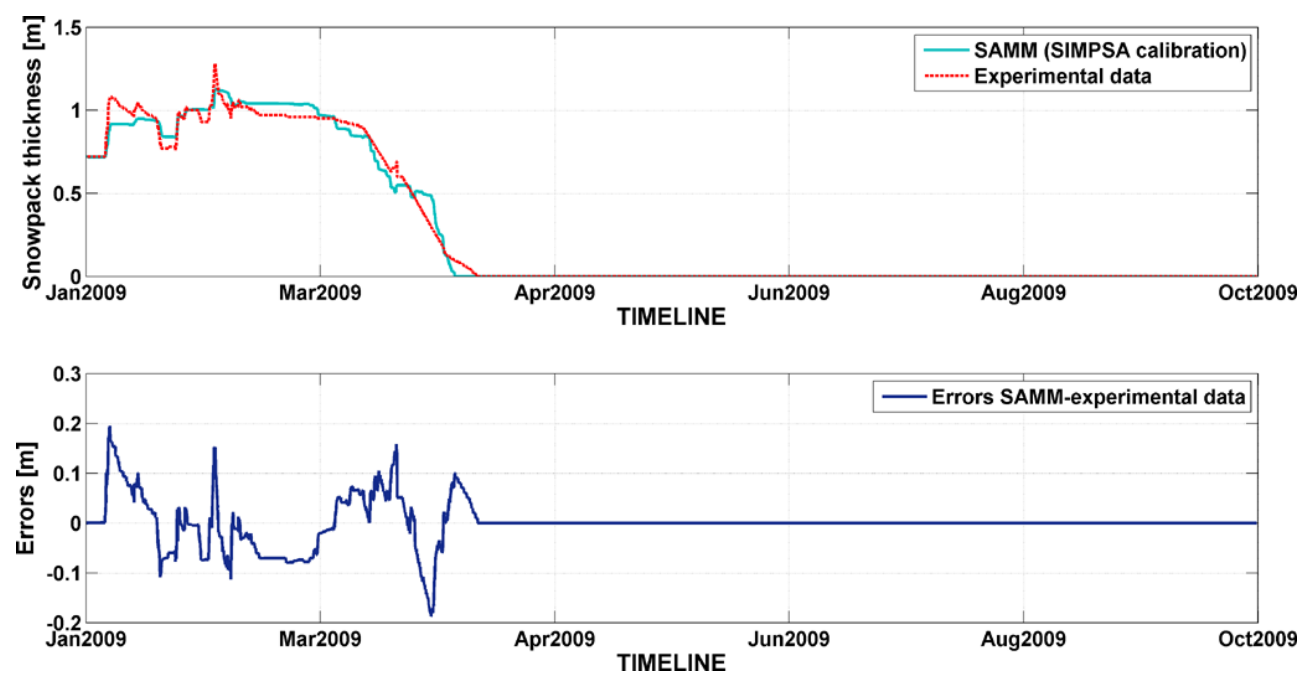

Fig. 4. Calibration of the model with the event January 2009-March 2009 registered by the Doccia di Fiumalbo station, using SIMPSA.

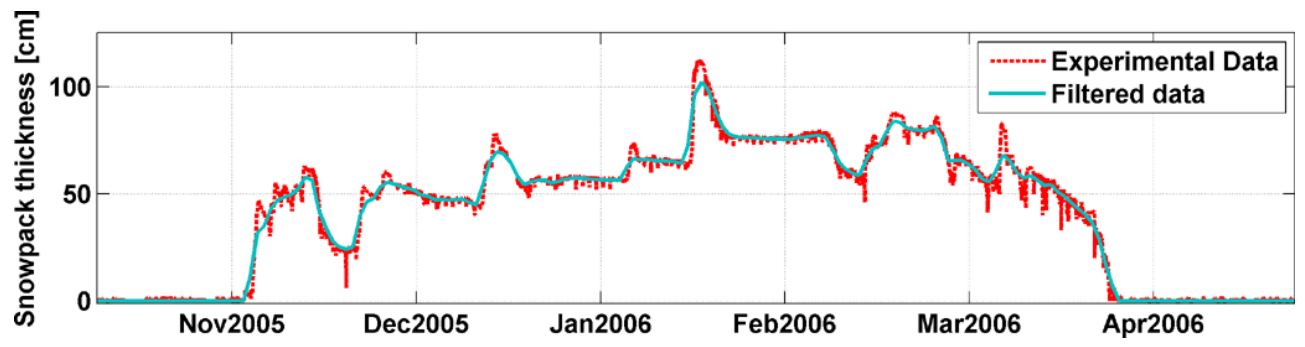

Fig. 5. Example of validation dataset: the experimental data, affected by sensor errors (above), are filtered with a moving average to clear out the noise and to estimate missing data.

a good robustness: in the accumulation phase, the increase by one degree of $T_{0}$ causes negligible errors, while for the melting phase higher errors are observed. Other models, in which the threshold temperature usually has values between -1 and $3^{\circ} \mathrm{C}$, also show that a temperature reduction leads to a higher error (US Army Corps of Engineers, 1956; Wigmosta et al., 1994).

\subsection{Comparison with temperature-index models}

SAMM is substantially an improved temperature index model based on 13 empirical parameters. Such a high number of parameters is more often encountered in distributed physically based models of snowpack evolution and it should be proved that the objective of correcting the point rainfall measurements of a rain gauge network could not be accomplished with a simpler formulation.

Therefore, to verify the improvement brought by SAMM with respect to simpler temperature-index models, we applied the equation proposed by Hock (2003):

$M=f_{\mathrm{m}}\left(T-T_{0}\right)$,

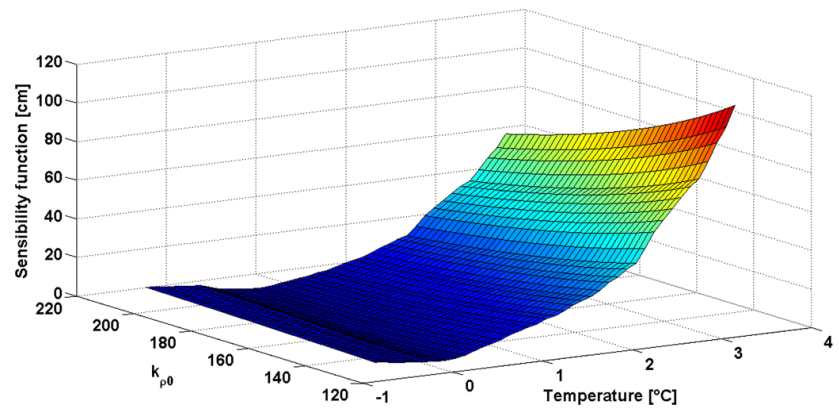

Fig. 6. Static sensitivity analysis of the model for the parameters $T_{0}$ (threshold temperature) and $k_{\rho 0}$.

where $M$ is the hourly melt, $f_{\mathrm{m}}$ is the melting factor and $T_{0}$ is a threshold temperature, integrated with an accumulation module expressed by $H^{\text {in }}=\left(\rho_{\mathrm{W}} / \rho_{\mathrm{s} 0}\right) \cdot H_{\mathrm{W}}$ (see Eq. 5).

In this case the calculation of the snowpack depth requires the use of 3 parameters: $f_{\mathrm{m}}, T_{0}$ and $\rho_{\mathrm{s} 0}$ (newly fallen snow density). We also performed a simulation with an improved temperature index model obtained coupling Eq. (20) for the melting process and Eq. (10) for the accumulation process. This approach makes use of 9 parameters and can be 
Table 4. Comparison of mean snowpack thickness and total mean error obtained for the different models with the validation dataset.

\begin{tabular}{lrrr}
\hline & & $\begin{array}{r}\text { Temperature-index } \\
+ \text { SAMM } \\
\text { accumulation } \\
\text { module }\end{array}$ & SAMM (this paper) \\
\hline Number of parameters & 3 & 9 & 13 \\
Mean snowpack thickness $(\mathrm{cm})$ & 61.31 & 56.83 & 49.20 \\
Total mean error $(\mathrm{cm})$ & 15.65 & 11.58 & 8.73 \\
\hline
\end{tabular}

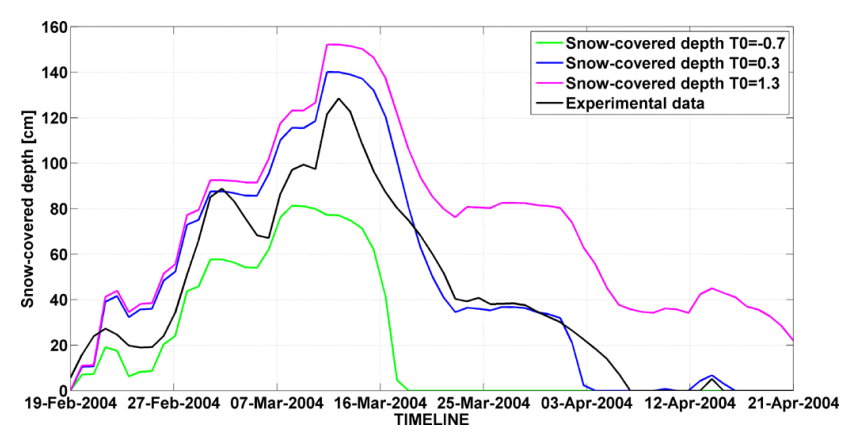

Fig. 7. Dynamic sensitivity analysis of the model for three different values of threshold temperature.

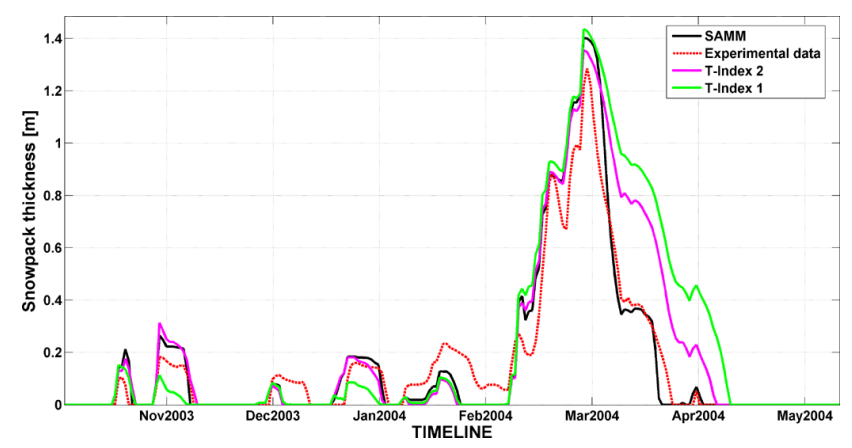

Fig. 8. Comparison between a temperature index model, an improved temperature index model, SAMM and experimental data for the period November 2003-May 2004 registered by Febbio station.

considered a compromise between the simple temperatureindex model proposed by Hock (2003) and the more sophisticated approach followed by SAMM.

Consistently with the methodology followed with SAMM, both temperature-index models were calibrated against the Doccia di Fiumalbo dataset using the optimisation algorithm described in Sect. 2.3; afterwards, they were validated against the Febbio station dataset. The outcomes of this test suggest that any further extension of the simple temperature index model brings some improvements with a consequent decrease of the error (Table 4). In Figs. 8 and 9 the results of the three different simulations are compared with the experimental data: it can be noticed that SAMM fits the real trend better than the other models. In the first validation

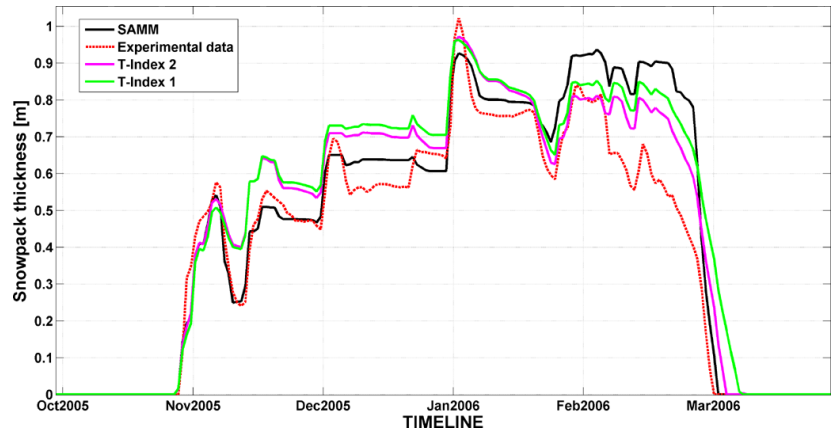

Fig. 9. Comparison between a temperature index model, an improved temperature index model, SAMM and experimental data for the period November 2005-March 2006 registered by Febbio station.

period (Fig. 8) SAMM has the lowest root mean square error (RMSE) ( $7.4 \mathrm{~cm}$ compared to $13.3 \mathrm{~cm}$ and $19.2 \mathrm{~cm}$ of the intermediate and the simple temperature index approaches, respectively). In the second validation period (Fig. 9) SAMM and the intermediate temperature index model show the same performance $(\mathrm{RMSE}=9.1 \mathrm{~cm})$, whereas the simple temperature index model has a RMSE of $12.0 \mathrm{~cm}$. In this case, the RSME of SAMM is highly influenced by a miscalculation of the last melting event (February-March 2006); however, it provides the best performance during the accumulation and the first melting phases.

\subsection{Integration between SAMM and SIGMA}

Sections 3.1 and 3.2 demonstrated that the most suitable methodology to take into account snow accumulation and melting in our case study is the SAMM model, calibrated with the simplex algorithm against the data of the Doccia di Fiumalbo station. This configuration was selected as a prototype to be integrated within the regional landslide warning system SIGMA. This integration is schematically explained in Fig. 10: SAMM acts like a filter on effective rainfall, depending on the thresholds temperature $T_{0}$.

If $T<T_{0}$, the snow accumulation module retains the rainfall (if present) and uses it to simulate the building of a snowpack, while a null precipitation enters the SIGMA warning system. 


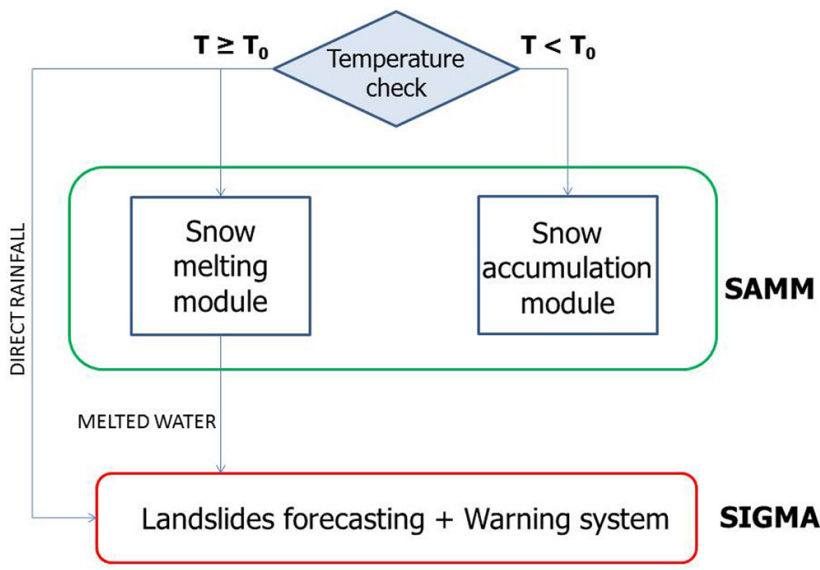

Fig. 10. Integrated system SAMM-SIGMA for landslides forecasting.

Table 5. Results of the simulation of an integrated use of SAMM and SIGMA (period 2004-2010).

\begin{tabular}{|c|c|c|c|c|}
\hline $\begin{array}{r}\text { Territorial } \\
\text { Unit }\end{array}$ & $\begin{array}{r}\text { Landslides } \\
\text { occurred }\end{array}$ & $\begin{array}{r}\text { Landslides } \\
\text { identified } \\
\text { (SIGMA) }\end{array}$ & $\begin{array}{c}\text { Landslides } \\
\text { identified } \\
\text { (SAMM+ } \\
\text { SIGMA) }\end{array}$ & $\begin{array}{r}\text { Improvement } \\
\text { (number of } \\
\text { landslides) }\end{array}$ \\
\hline 9 & 151 & 101 & 105 & +4 \\
\hline 12 & 156 & 84 & 112 & +28 \\
\hline 15 & 127 & 83 & 105 & +22 \\
\hline
\end{tabular}

If $T \geq T_{0}$, the snow melting module returns to SIGMA the water equivalent of snow melting (if present) and the actual raining quantity (if present).

To verify the effectiveness of this approach, we simulated an integrated use of SAMM and SIGMA using rainfall, temperature and landslide data of the period 2004-2010. For obvious reasons, SAMM could be implemented only in the 11 TUs equipped with a heated pluviometer (the remaining 8 TUs are provided with standard rain gauges since snow is uncommon). In 8 TUs, SIGMA outputs resulted scarcely influenced by the corrections provided by SAMM, because no consistent snowfalls were registered during the test period. The use of SAMM had a relevant impact on SIGMA outputs in 3 TUs, where the territory is predominantly mountainous and where heavy snowfalls struck during the test period. Here, the landslides forecasting capability was evidently enhanced by the use of the snow model, as 54 more snowmelt-triggered landslides were identified with its aid (Table 5). Thus, the primary objective of the model (predicting snowmelt-triggered landslides) was successfully achieved.

Table 6 reports a more complete overview of the validation. In the three snow-affected TUs, the ground truth was compared with the daily outputs of SIGMA and with those obtained after the integration with SAMM. These statistics highlight that the improved effectiveness in forecasting landslides has the counterweight of a slightly higher number of
Table 6. Validation statistics of the landslide warning system with (SAMM + SIGMA) and without (SIGMA) the contribution of the snow accumulation melting model.

\begin{tabular}{lrr}
\hline & SIGMA & SIGMA + SAMM \\
\hline$a$ True positives (hits) & 72 & 82 \\
$b$ false positives (false alarms) & 255 & 295 \\
$c$ false negatives (misses) & 75 & 65 \\
$d$ true negatives & 7269 & 7229 \\
Sensitivity $=a /(a+c)$ & 0.48 & 0.55 \\
Specificity $=d /(b+d)$ & 0.96 & 0.96 \\
Likelihood ratio $=$ sensitivity $/(1-$ specificity) & 14.45 & 14.22 \\
Efficiency $(a+d) /(a+b+c+d)$ & 0.95 & 0.95 \\
\hline
\end{tabular}

false alarms; however, since in general all statistics show an improvement or an almost negligible decrease, the contribution of SAMM could be evaluated as positive (Table 6).

\section{Conclusions}

We developed a snow accumulation/melting model (SAMM) aimed at improving (in case of snowmelts and snowfalls) the performances of a regional scale landslide warning system based on statistical rainfall thresholds.

SAMM is based on two modules modelling the snow accumulation and the snowmelt processes. Each module is composed by two equations: a conservation of mass equation models the snowpack thickness and an empirical equation takes into account the snow density. The case study is affected by a relevant scarcity of data: only air temperature and rainfall recordings are available for use in future real-time applications, therefore to solve the equations of the model, 13 static empirical parameters were introduced and their optimum value was estimated by means of the simplex flexible optimisation algorithm (Nelder and Mead, 1965; MarsiliLibelli, 1992). A cross-validation procedure and a sensitivity analysis highlighted that the parametric identification of the model was robust and the validation, which was carried out over an independent dataset, demonstrated that the mean error of the model was contained within the rain gauge instrumental error. To a closer insight, however, in some portions of the validation timeline, the modelled snowpack thickness is affected by underestimation or overestimation that can reach $30 \mathrm{~cm}$. Those mismatches are probably heavily conditioned by the necessity of using only rainfall and temperature as input parameters, without explicitly considering other very important physical factors such as solar radiation, wind, atmospheric pressure, air humidity and so on.

The simple formulation of SAMM is conceived to be integrated with empirical landslide forecasting procedures: a threshold temperature (the most important among the aforementioned 13 empirical parameters) switches between the snow accumulation and the snow melting module and adjusts the value of the rainfall amount measured by the rain gauges accordingly. 
The comparison with two simpler temperature index models (a simple model based on 3 empirical parameters and an improved version based on 9 parameters and incorporating a conservation of mass equation) reveals that the quality of the results improves with the complexity of the formulation (i.e. with the number of parameters taken into account). In this regard, SAMM could be considered an intermediate approach between temperature index- and physically based models: from an operational point of view it simply uses air temperature as an index to take into account snow melting and accumulation, but the value of the threshold temperature (as all other static parameters involved in the equations) are defined by means of a semi-physical approach, which starts from a conservation of mass equation and uses empirical approximations and calibrations to overcome the unavailability of dynamic data for an operational employment of the model at regional scale.

Experimental simulations showed that SAMM could be fruitfully integrated into a regional scale landslide warning system: SAMM operates a redistribution of water (coming from rainfall or from snowmelt) that positively influences the outputs of the warning system and the delayed water release allows to better constrain the infiltration of water into the ground. The use of SAMM during the period 2004-2010 would have allowed the forecasting of 54 landslides triggered by snow melting that were not detected by the conventional warning system. The use of SAMM was possible only in the TUs equipped with heated rain gauges, and it was particularly successful in the mountainous TUs, where solid precipitation is more recurrent, while in the hilly TUs where snow is an exceptional phenomenon (and oftentimes is mixed with rain) the use of SAMM provided limited benefits. In particular, the integrated landslide warning system developed in this study presents some advantages: the extreme simplicity and rapidity of the forecasting procedure; the limited number of input data required for calibration and for the operational use (temperature and precipitation); the possibility of exporting the procedure wherever a sufficiently organised meteorological network is present (after a site-specific calibration); the immediate interpretation of the final output, which can be directly put in correspondence with the criticality levels adopted by the Civil Protection Authority.

Acknowledgements. This research has been financed by the Civil Protection Agency of the Emilia Romagna region. The authors would like to thank in particular Angela Gallucci, Sabrina Primerano, Antonio Monni and Demetrio Egidi. ARPA Emilia-Romagna (Regional Agency for Environmental Protection in the EmiliaRomagna region), is fully acknowledged for having provided part of the data used in this work. Many thanks to Patrizia Musina for the revision of the English. Lastly, the Editor and three anonymous referees are fully acknowledged for their precious and constructive comments.

Edited by: B. Schaefli

\section{References}

Aleotti, P.: A warning system for rainfall-induced shallow failures, Eng. Geol., 73, 247-265, 2004.

Bartelt, P. and Lehning, M.: A physical SNOWPACK model for the Swiss avalanche warning: Part I: numerical model, Cold Reg. Sci. Technol., 35, 123-145, 2002.

Bartlett, P. A., MacKay, M. D., and Verseghy, D. L.: Modified snow algorithms in the Canadian land surface scheme: Model runs and sensitivity analysis at three boreal forest stands, Atmos. Ocean, 44, 207-222, 2006.

Baum, R. L., Godt J. W., and Savage, W. Z.: Estimating the timing and location of shallow rainfall induced landslides using a model for transient, unsaturated infiltration, J. Geophys. Res., 115, F03013, doi:10.1029/2009JF001321, 2010.

Bernier, N. B., Bélair, S., Bilodeau, B., and Tong, L.: Near-Surface and Land Surface Forecast System of the Vancouver 2010 Winter Olympic and Paralympic Games, J. Hydrometeorol., 12, 508530, 2011.

Bloschl, G., Kirnbauer, R., and Gutknecht, D.: Distributed snowmelt simulations in an alpine catchment 1 . Model evaluation on the basis of snow cover patterns, Water Resour. Res., 27 3171-3179, 1991.

Brun, E., Martin, E., Simon, V., Gendre, C., and Coleou, C.: An energy and mass balance model of snowcover suitable for operational avalanche forecasting, J. Glaciol., 35, 333-342,1989.

Cannon, S. H., Boldt, E. M., Laber, J. L., Kean, J. W., and Staley, D. M.: Rainfall intensity-duration thresholds for postfire debrisflow emergency-response planning, Nat. Hazards, 59, 209-236, 2011.

Cardinali, M., Ardizzone, F., Galli, M., Guzzetti, F., and Reichenbach, P.: Landslide triggered by rapid snow melting: the December 1996-January 1997 event in Central Italy, in: Proceedings European Geophysical Society $1^{\circ}$ Plinius Conference on Mediterranean Storms, Maratea, Italy, 14-16 October 1999, 439-448, 2000.

Cardoso, M. E., Salcedo, R. L., and de Azevedo, S. E.:The simplexsimulated annealing approach to continuous non-linear optimization, Comput. Chem. Eng., 20, 1065-1080, 1996.

Ceaglio, E., Meusburger, K., Freppaz, M., Zanini, E., and Alewell, C.: Estimation of soil redistribution rates due to snow cover related processes in a mountainous area (Valle d'Aosta, NW Italy), Hydrol. Earth Syst. Sci., 16, 517-528, doi:10.5194/hess-16-5172012, 2012.

Chleborad, A. F.: Temperature, snowmelt, and the onset of spring season landslides in the central Rocky Mountains, US Geological Survey, Open-File Report 97-27, 35 pp., 1997.

Damiano, E., Olivares, L., and Picarelli, L.: Steep-slope monitoring in unsaturated pyroclastic soils, Eng. Geol., 137-138, 1-12, 2012.

Garen, D. C. and Marks, D.: Spatially distributed energy balance snowmelt modelling in a mountainous river basin: estimation of meteorological inputs and verification of model results, J. Hydrol., 315, 126-153, 2005.

Gokceoglu, C., Sonmez, H., Nefeslioglu, H. A., Duman, T. Y., and Can, T.: Kuzulu landslide (Sivas, Turkey) and landslidesusceptibility map of its near vicinity, Eng. Geol., 81, 65-83, 2005.

Gustafsson, D., Waldner, P. A., and Stähli, M.: Factors governing the formation and persistence of layers in a subalpine snowpack, 
Hydrol. Process., 18, 1165-1183, doi:10.1002/hyp.1398, 2004.

Guzzetti, F.: Landslide fatalities and the evaluation of landslide risk in Italy, Eng. Geol., 58, 89-107, 2000.

Guzzetti, F., Reichenbach, P., Cardinali, M., Ardizzone, F., and Galli, M.: The impact of landslides in the Umbria region, central Italy, Nat. Hazards Earth Syst. Sci., 3, 469-486, doi:10.5194/nhess-3-469-2003, 2003.

Hedstrom, N. R. and Pomeroy, J. W.: Measurments and modeling of snow interception in the boreal forest, Hydrol. Process., 12, 1611-1625, 1998.

Herrero, J., Polo, M. J., Moñino, A., and Losada, M. A.: An energy balance snowmelt model in a Mediterranean site, J. Hydrol., 371, 98-107, 2009.

Himmelblau, D. M.: Applied Non-Linear Programming, McGrawHill, New York, 1972.

Hock, R.: A distributed temperature-index ice- and snowmelt model including potential direct solar radiation, J. Glaciol., 45, 101$111,1999$.

Hock, R.: Temperature index melt modelling in mountain areas, J. Hydrol., 282, 104-115, 2003.

Jost, G., Moore, R. D., Smith, R., and Gluns, D. R.: Distributed temperature-index snowmelt modelling for forested catchments, J. Hydrol., 420-421, 87-101, 2012.

Kawagoe, S., Kazama, S., and Sarukkalige, P. R.: Assessment of snowmelt triggered landslide hazard and risk in Japan, Cold Reg. Sci. Tech., 58, 120-129, 2009.

Keefer, D. K., Wilson, R. C., Mark, R. K., Brabb, E. E., Brown, W. M. III, Ellen, S. D., Harp, E. L., Wieczorek, G. F., Alger, C. S., and Zatkin, R. S.: Real-time landslide warning during heavy rainfall, Science, 238, 921-925, 1987.

Kustas, W. P., Rango, A., and Uijlenhoet, R.: A simple energy budget algorithm for the snowmelt runoff model, Water Resour. Res., 30, 1515-1527, 1994.

Lagomarsino, D., Segoni, S., Fanti, R., and Catani, F.: Updating and tuning a regional-scale landslide early warning system, Landslides, 10, 91-97, doi:10.1007/s10346-012-0376-y, 2013.

Lakhankar, T. Y., Muñoz, J., Romanov, P., Powell, A. M., Krakauer, N. Y., Rossow, W. B., and Khanbilvardi, R. M.: CREST-Snow Field Experiment: analysis of snowpack properties using multifrequency microwave remote sensing data, Hydrol. Earth Syst. Sci., 17, 783-793, doi:10.5194/hess-17-783-2013, 2013.

Li, H.-Y. and Wang, J.: Simulation of snow distribution and melt under cloudy conditions in an Alpine watershed, Hydrol. Earth Syst. Sci., 15, 2195-2203, doi:10.5194/hess-15-21952011, 2011.

Marks, D., Domingo, J., Susong, D., Link, T., and Garen, D.: A spazially distributed energy balance snowmelt model for application in mountain basins, Hydrol. Process., 13, 1935-1959, 1999.

Marsili-Libelli, S.: Parameter estimation of ecological models, Ecol. Model., 62, 233-258, 1992.

Martelloni, G., Segoni, S., Fanti, R., and Catani, F.: Rainfall thresholds for the forecasting of landslide occurrence at regional scale, Landslides, 9, 485-495, 2012.

Martin, E., Timbal, B., and Brun, E.: Downscaling of general circulation model outputs: simulation of the snow climatology of the French Alps and sensitivity to climate change, Clim. Dynam., 13, 45-56, 1996.
Naudet, V., Lazzari, M., Perrone, A., Loperte, A., Piscitelli, S., and Lapenna, V.: Integrated geophysical and geomorphological approach to investigate the snowmelt-triggered landslide of Bosco Piccolo village (Basilicata, southern Italy), Eng. Geol., 98, 156167, 2008.

Nelder, J. A. and Mead, R.: A simplex method for function minimization, Comput. J., 7, 308-313,1965.

Rango, A. and Martinec, J.: Revisiting the degree-day method for snowmelt computations, Water Resour. Bull., 31, 657-669, 1995.

Ryan, W. A., Doesken, N. J., and Fassnacht, S. R.: Preliminary results of ultrasonic snow depth sensor testing for National Weather Service (NWS) snow measurements in the US, Hydrol. Process., 22, 2748-2757, 2008.

Rosi, A., Segoni, S., Catani, F., and Casagli N.: Statistical and environmental analyses for the definition of a regional rainfall thresholds system for landslide triggering in Tuscany (Italy), J. Geogr. Sci., 22, 617-629, 2012.

Rossi, G., Catani, F., Leoni, L., Segoni, S., and Tofani, V.: HIRESSS: a physically based slope stability simulator for HPC applications, Nat. Hazards Earth Syst. Sci., 13, 151-166, doi:10.5194/nhess-13-151-2013, 2013.

Rousselot, M., Durand, Y., Giraud, G., Merindol, L., and Daniel, L.: Analysis and forecast of extreme new-snow avalanches: a numerical study of the avalanche cycles of February 1999 in France, J. Glaciol., 56, 758-770, 2010.

Schmidt, R. A. and Gluns, R.: Snowfall interception on branches of three conifer species, Can. J. Forest Res., 21, 1262-1269, 1991.

Segoni, S., Leoni, L., Benedetti, A. I., Catani, F., Righini, G., Falorni, G., Gabellani, S., Rudari, R., Silvestro, F., and Rebora, N.: Towards a definition of a real-time forecasting network for rainfall induced shallow landslides, Nat. Hazards Earth Syst. Sci., 9, 2119-2133, doi:10.5194/nhess-9-2119-2009, 2009.

Segoni, S., Rossi, G., and Catani, F.: Improving basin scale shallow landslide modelling using reliable soil thickness maps, Nat. Hazards, 61, 85-101, 2012.

Takeuchi, Y., Torita, H., Nishimura, K., and Hirashima, H.: Study of a large-scale dry slab avalanche and the extent of damage to a cedar forest in the Makunosawa valley, Myoko, Japanm, Ann. Glaciol., 52, 119-128, 2011.

US Army Corps of Engineers: Snow hydrology, summary report of the snow investigations, Technical report, US Army Corps of Engineers, North Pacific Division, Portland, Oregon, 1956.

Wieczorek, G. F.: Landslide triggering mechanisms, in: Landslides: Investigation and Mitigation, edited by: Turner, A. K. and Schuster, R. L., Washington DC, Transportation Research Board, National Research Council, Special Report, 76-90, 1996.

Wigmosta, M. S., Vail, L. W., and Lettenmaier, D. P.: A distributed hydrology-vegetation model for complex terrain, Water Resour. Res., 30, 1665-1679, 1994.

Zanotti, F., Endrizzi, S., Bertoldi, G., and Rigon, R.: The GEOTOP snow module, Hydrol. Process., 18, 3667-3679, doi:10.1002/hyp.5794, 2004. 